\title{
Reliable multi period multi product supply chain design with facility disruption
}

\author{
Mehdi Rafiei $^{\mathrm{a}}$, Mohammad Mohammadi ${ }^{\mathrm{b}}$ and S.A. Torabi
}

\begin{abstract}
${ }^{a, b}$ Department of Industrial Engineering, Faculty of Engineering, Kharazmi University, Karaj, Iran ${ }^{c}$ Department of Industrial Engineering, College of Engineering, University of Tehran, Tehran, Iran CHRONICLE ABSTRACT

Article history:

Received October 2, 2012

Received in Revised Format

January 23, 2013

Accepted February 15, 2013

Available online

February 182013

Keywords:

Facility disruptions

Metaheuristics

Reliable network design

Multi period multi product supply

chain

This paper presents a strategic multi segment, multi period and multi-product supply chain management to meet reliable networks for handling disruptions strike. We present a mixedinteger programming model whose objective is to minimize the expected cost composed of probability and cost of occurrence in each scenario. The proposed model of this paper considers time value of money for each operation and transportation cost. We attempt to minimize expected costs by considering the levels of inventory, back-ordering, the available machine capacity and labor levels for each source, transportation capacity at each transshipment node and available warehouse space at each destination. The problem is generalized by taking into account backup supplier with reserved capacity and backup transshipment node that, which satisfies demands at higher price without disruption facility. We use a priority-based genetic algorithms encoding to solve the proposed problem under multi period and multi product conditions. The performance of the proposed model is examined using some instances.
\end{abstract}

(C) 2013 Growing Science Ltd. All rights reserved.

\section{Introduction}

Suppliers, retailers and distribution centers are essential components of supply chain and they need to be designed properly for long-term networking plans. There are literally many mathematical models to solve a variety of supply chain network design problems (e.g. Magnanti \& Wong, 1984; Owen \& Daskin, 1998; Daskin et al., 2005; Meixell \& Gargeya, 2005). However, many facilities are not reliable in today's industries and they may fail or disrupted during the design phase. The popularization of the "lean" concept, which allows minimum redundancy, and the development of global supply chains have created some challenges for optimal design problems. From the terrorist attacks of 9/11 to the catastrophic devastation caused by Hurricane Sandy, recent events (Barrionuevo \& Deutsch, 2005; Latour, 2001; Mouawad, 2005) have raised higher risks from disruptions. Many people state that today international supply chains are strong and reliable, but in reality, many are fragile and easily disrupted when the unexpected incidents occur. For instance, in 2008, the delivery of the Dreamliner 787 was interrupted because of delays in supply for some critical components and

* Corresponding author. Tel: +989124446245

E-mail addresses: Mohammadi@tmu.ac.ir (M. Mohammadi)

(C) 2013 Growing Science Ltd. All rights reserved.

doi: $10.5267 /$ j.dsl.2013.02.002 
the firm was fined because of delay (Bathgate \& Hayashi, 2008). In 2011, a disastrous earthquake and the following tsunami struck Japan, causing heavy casualties and property losses. As a result, the sequences of this trouble adventures as plant damage, transportation blockage or power outages interrupted the production in a broad spectrum of the country's industries (Clark \& Takahashi, 2011).

In this paper, we study the problem of designing a multi segment, multi period and multi product supply chain network, which consists of supply, transshipment, and demand nodes with reserved capacity for back up supplier. Reserved capacity used to deal with disruption is determined by decision maker and owner of back up supplier. The price of products under reserved capacity is cheaper than price of products upper reserved capacity. Once such a supply chain infrastructure is built, it will be very difficult and costly to modify the design. Therefore, it is important to design supply chain systems that attain continuity and efficiency in the presence of all kinds of disruptions from the start.

\section{Literature review}

There is no doubt that we need to design supply chains, which are resilient to disruptions using different robust strategies for mitigating supply chain disruptions. This will enable a supply chain to function smoothly and to serve customers during disruptions, continually (Tang, 2006). Kleindorfer and Saad (2005) presented a conceptual framework for disruption risk management in supply chains, which is based on the risk management literature and models of supply chain coordination. Drezner (1987) studied the unreliable p-median and (p, q)-center location problems, in which a facility had a given probability of becoming inactive. Snyder and Daskin (2005) presented reliable uncapacitated fixed-charge location problem (UFLP) and the P-median problem aimed to minimize a weighted sum of the nominal cost when no disruptions occur and the expected cost accounting for random disruptions were considered. For tractability, they made a strong assumption that all facilities had the same probability of failure. Berman et al. (2007), Cui et al. (2010), Li and Ouyang (2010), Lim et al. (2009), Lim et al. (2010), Shen et al. (2007), Snyder et al. (2006), and Zhan et al. (2008) all considered models similar to Snyder and Daskin's but used variety of modeling approaches else the uniform-disruption-probability assumption. Bunschuh et al. (2006) presented disruptions in a multiechelon supply chain network and to improve the robustness of the network, a redundancy was created. In addition, they added supplier sourcing constraints, which give upper bounds on the total amount a customer can source from a single supplier to the model. This approach forces customer to select multiple suppliers and does not explicitly include the possibility of disruption for each supplier. Snyder et al. (2006) introduced an expected-cost objective rather than a robustness constraint and wide range of strategic planning models for facility location and supply chain network design problems under the threat of disruptions. Scapparra and Cappanera (2010) considered a network design problem with a shortest-path objective in presence of disruption. In addition, Peng Peng et al. (2011) presented min-cost-flow-type objective for above model, which seemed more suitable. In these papers, supply chain's models are single product and single period. However, in practical situations, many of disruption have certain duration like strike, and more supply chains are multi period and multi product we may consider decision maker to include inventory level for dealing with disruption or backorder demand to next period.

The rest of the paper is organized as follows. In Section 3, we formulate the multi segments, multiproduct and multi-time period problem (MSMDPD). A priority-based GA is proposed in Section4. We report our numerical results in Section 5. Section 6 concludes our study.

\section{Problem formulation}

\subsection{Problem description, assumptions, and notations}

In this section, we present multi segments, multi-product and multi-period problem (MSMDPD). This study assumes that the logistics center of a supply chain attempts to design the suitable MSMDPD 
integration plan for $n u$ types of homogeneous goods to satisfy demand of destinations over a planning horizon $h u$ with facilities as sources (factories), transshipments (distribution centers). Each source affected by disruption has a supply of the commodity available for distribution to different transshipments. In addition, transshipments under risk of disruptions must fulfill demand of each destination with received commodities from supplier. Finally, each destination also forecasts the demand for the commodity and receives from its sources. This paper focuses on presenting an integrated plan to deal with disruption risk as:

1. How much commodities must care to next period for suppliers with no disruption in a certain potential scenario of disruption.

2. How much of commodities must be back ordered to satisfy demand within the next period in disruption condition.

3. How much of commodities must be provided from external supplier with no interruption in external transshipment.

To address these concerns, we propose MSMDPD problem and to meet this goal, the following assumptions are considered.

(1) Fixed cost at each source and each transshipment of product $n$ in period $h$ are independent from size of ordering.

(2) All of the objective functions and constraints are linear equations.

(3) Operation costs at each source and distribution costs on a given route are directly proportional to the units manufactured and shipped, respectively.

(4) The escalating factors of the related operating cost categories are certain over the next $H$ planning horizon.

(5) The actual labor levels, machine capacity, transportation volume and warehouse space in each period cannot exceed their respective maximum available levels.

(6) Either the sources can satisfy, or back order the forecasted demand at each destination over a particular period. However, the sources must fulfill the backorder in the next period.

(7) Transportation cost from main transshipments to other destinations is less than from main backup transshipment to other destinations.

(8) Transportation cost from sources to backup transshipment is higher than from sources to main transshipments.

(9) Transportation cost from backup supplier to transshipments as back up and main is higher than other suppliers are.

(10) Operation cost in backup supplier, which is higher than any main supplier, divided in two segments as operation cost on under reserved capacity level and operation cost on upper reserved capacity level. First kind of operation cost is less than second kind cost.

(11) Disruption will be lost inventory level from previous period, capacity of machine and available labor level of each product in each period.

Assumption 1 states fixed cost in our supply chain is more expensive than operation costs and independent from operation volume and must be bought at each period to satisfy demand of each product. Assumptions 2 to 4 indicate linearity, proportionality and certainty properties must be technically satisfied as a standard LP form. Assumption 5 represents the limits on the maximum 
available labor levels, machines, transportation and warehouse capacities. Assumption 6 details the necessary level of satisfaction in the portion of demand at each destination during any period. A business can backorder the remaining demand, but they should not carry over the backorders for more than one period. Assumption 7, 8 and 9, 10 addresses the higher expenses of using backup source and back up transshipment node than main supplier in our supply chain because of its location on a foreign country or region. This study uses the following notation.

\section{Index sets}

$\begin{array}{cl}i & \text { source } i=1,2, \ldots, m \\ d & \text { back up source } \\ n & \text { product type } n=1,2, \ldots, n u \\ h & \text { planning period } h=1,2, \ldots, h u \\ t & \text { transshipment } t=1,2, \ldots, t u \\ t d & \text { back up transshipment } \\ j & \text { destination } \mathrm{j}=1,2, \ldots, m p \\ s & \text { disruption scenario } s=1,2, \ldots, \text { sce }\end{array}$

Decision variables

\section{A. Integer variables}

$\mathrm{VA}_{\mathrm{inh}} \quad$ production of product $n$ by source $i$ in period $h$,

$\mathrm{VA}_{\mathrm{dnh}}$ production of product $n$ by backup source $\mathrm{d}$ in period $h$ under reserved capacity level,

$\operatorname{VAd}_{\mathrm{dnh}}$ production of product $n$ by backup source $d$ in period $h$ upper reserved capacity level,

$\mathrm{VC}_{\text {inh }} \quad$ inventory level of product $n$ by source $i$ in period $h$,

$\mathrm{VD}_{\text {inh }} \quad$ backordering of product $\mathrm{n}$ by source $i$ in period $h$,

$\mathrm{VE}_{\text {inht }} \quad$ units distributed of product $n$ from source $i$ to transshipment $t$ in period $h$,

$V_{\text {inhtd }}$ units distributed of product $n$ from source $i$ to back up transshipment $t d$ in period $h$

$V_{\mathrm{dnht}}$ units distributed of product $n$ from back up source $d$ to transshipment $t$ in period $i$,

$\mathrm{VE}_{\mathrm{dnhtd}}$ units distributed of product $n$ from back up source $d$ to back up transshipment $t d$ in period $h$

$\mathrm{VB}_{\text {tnhj }} \quad$ units distributed of product $n$ from transshipment $t$ to destination $j$ in period $h$

$\mathrm{VB}_{\mathrm{tdnhj}}$ units distributed of product $n$ from back up transshipment $t d$ to destination $j$ in period $h$,

\section{B. Binary variables:}

$\mathrm{xW}_{\mathrm{inh}} \quad$ Binary variable for order of source $i$ of product $n$ in period $h$,

$\mathrm{xv}_{\mathrm{tnh}} \quad$ Binary variable for chose of transshipment $t$ of product $n$ in period $h$,

\section{Parameters:}

$\mathrm{f}_{\mathrm{in} 1} \quad$ fixed cost of product $n$ by source $i$ in period 1 ,

$\mathrm{f}_{\mathrm{tn} 1} \quad$ fixed cost of product $n$ by transshipment $t$ in period 1 ,

$\widetilde{\mathrm{e}_{\mathrm{f}}} \quad$ escalating factor of regular production cost,

$\mathrm{a}_{\text {in1 }} \quad$ unit production cost of product $n$ by source $i$ in period 1 ,

$\mathrm{a} 1_{\mathrm{dn} 1}$ unit production cost of product $n$ by back up source $d$ in period 1 under reserved capacity level,

$\mathrm{a} 2 \mathrm{dn} 1 \quad$ unit production cost of product $n$ by back up source $d$ in period lupper reserved capacity level,

$\widetilde{\mathrm{e}_{\mathrm{a}}} \quad$ escalating factor of regular production cost,

$\tilde{c}_{\text {in1 }} \quad$ inventory unit carrying cost of product $n$ by source $i$ in period 1 ,

$\widetilde{\mathrm{e}_{\mathrm{c}}} \quad$ escalating factor of inventory carrying cost, 
$\tilde{\mathrm{d}}_{\text {in } 1} \quad$ backordering unit cost of product $n$ by source $i$ in period 1 ,

$\widetilde{\mathrm{e}_{\mathrm{d}}} \quad$ escalating factor of backordering cost,

$\mathrm{k}_{\mathrm{in} 1 \mathrm{t}} \quad$ delivery unit cost of product $\mathrm{n}$ from source $i$ to transshipment $t$ in period 1 ,

$\mathrm{k}_{\mathrm{in} 1 \mathrm{td}} \quad$ delivery unit cost of product $\mathrm{n}$ from source $i$ to backup transshipment $t d$ in period 1 ,

$\mathrm{k}_{\mathrm{dn} 1 \mathrm{t}} \quad$ delivery unit cost of product $\mathrm{n}$ from backup source $d$ to transshipment $t$ in period 1 ,

$\mathrm{k}_{\mathrm{dn} 1 \mathrm{td}}$ delivery unit cost of product $\mathrm{n}$ from backup source $d$ to backup transshipment $t d$ in period 1,

$\widetilde{\mathrm{e}_{\mathrm{k}}} \quad$ escalating factor of delivery cost,

$\mathrm{b}_{\mathrm{tn} 1 \mathrm{j}} \quad$ delivery unit cost of product $n$ from transshipment $t$ to destination $j$ in period 1 ,

$\mathrm{b}_{\mathrm{tdn} 1 \mathrm{j}} \quad$ delivery unit cost of product $n$ from back up transshipment $t d$ to destination $j$ in period 1 ,

$\widetilde{\mathrm{e}_{\mathrm{b}}} \quad$ escalating factor of delivery cost,

$\mathrm{D}_{\text {nhj }} \quad$ demand of product $n$ of destination $j$ in period $h$,

$l_{\text {inh }} \quad$ unit labor hour of product $n$ is used by source $i$ in period $h$,

$\mathrm{L}_{\mathrm{inh}} \quad$ maximum labor hour levels available of product $\mathrm{n}$ by source $i$ in period $h$,

$r_{i n h} \quad$ unit machine hour of product $\mathrm{n}$ produced by source $i$ in period $h$,

$\mathrm{M}_{\mathrm{inh}} \quad$ maximum machine capacity available of product $n$ by source $i$ in period $h$,

$\mathrm{x}_{\mathrm{dnh}} \quad$ reserved capacity of product $n$ by back up source $d$ in period $h$,

$\mathrm{V}_{\mathrm{n}} \quad$ unit warehouse space of product $n$,

$\mathrm{W}_{\mathrm{nhj}} \quad$ maximum warehouse space available of product $\mathrm{n}$ of destination $\mathrm{j}$ in period $h$,

$\mathrm{Mt}_{\mathrm{tnh}}$ maximum capacity available of product $n$ by transshipment $t$ in period $h$,

$\mathrm{st}_{\mathrm{tnh}} \quad$ unit landed and loaded hour of product $n$ by transshipment $t$ in period $h$,

$\mathbf{P}_{\mathbf{s}} \quad$ Probability of disruption scenario $s$,

$\mathrm{xc}_{\mathrm{inh}} \quad 1$ if supplier $i$ of product $n$ is disrupted at period $\mathrm{h}$ in scenario $\mathrm{s}, 0$ otherwise,

$\mathrm{xt}_{\mathrm{tnh}} \quad 1$ if transshipment $t$ of product $n$ is disrupted at period $h$ in scenario $\mathrm{s}, 0$ otherwise.

\subsection{Original multi segment multi-product and multi-time period MSMDPD model}

\subsubsection{Objective function}

After reviewing the literature and considering practical situations, the original multi segment multiproduct and multi-period MSMDPD model designed in this paper selects the total manufacturing, transportation and distribution costs as the objective function of each scenario. Total cost is expected cost of all scenarios. In practical MSMDPD problems, a DM considers typical related operating costs, inventory and backordering levels, available resources and capacities, market demand, product life cycle, employment laws, probability of occurrence scenario and other factors to either minimize total manufacturing and distribution costs or maximize profits. Accordingly, the following illustrates the function of expected cost.

$$
\begin{aligned}
& \mathrm{Z}=\sum_{\mathrm{s}=1}^{\text {sce }} \mathrm{P}_{\mathrm{s}}\left(\sum_{\mathrm{i}=1}^{\mathrm{m}} \sum_{\mathrm{n}=1}^{\mathrm{nu}} \sum_{\mathrm{h}=1}^{\mathrm{hu}} \mathrm{a}_{\mathrm{in} 1} * \mathrm{VA}_{\mathrm{inh}}\left(1+\mathrm{e}_{\mathrm{a}}\right)^{\mathrm{h}-1}+\sum_{\mathrm{n}=1}^{\mathrm{nu}} \sum_{\mathrm{h}=1}^{\mathrm{hu}} \mathrm{a}_{\mathrm{dn} 1} * \mathrm{VA}_{\mathrm{dnh}}\left(1+\mathrm{e}_{\mathrm{a}}\right)^{\mathrm{h}-1}\right. \\
& +\sum_{\mathrm{n}=1}^{\mathrm{nu}} \sum_{\mathrm{h}=1}^{\mathrm{hu}} \mathrm{a}_{\mathrm{dn} 1} * \operatorname{VAd}_{\mathrm{dnh}}\left(1+\mathrm{e}_{\mathrm{a}}\right)^{\mathrm{h}-1}+\sum_{\mathrm{i}=1}^{\mathrm{m}} \sum_{\mathrm{n}=1}^{\mathrm{nu}} \sum_{\mathrm{h}=1}^{\mathrm{hu}} \mathrm{c}_{\mathrm{in} 1} * \mathrm{VC}_{\mathrm{inh}}\left(1+\mathrm{e}_{\mathrm{c}}\right)^{\mathrm{h}-1} \\
& +\sum_{\mathrm{i}=1}^{\mathrm{m}=1} \sum_{\mathrm{n}=1}^{\mathrm{nu}} \sum_{\mathrm{h}=1}^{\mathrm{hu}} \mathrm{d}_{\mathrm{in} 1} * \mathrm{VD}_{\mathrm{inh}}\left(1+\mathrm{e}_{\mathrm{d}}\right)^{\mathrm{h}-1}+\sum_{\mathrm{i}=1}^{\mathrm{m}} \sum_{\mathrm{n}=1}^{\mathrm{nu}} \sum_{\mathrm{h}=1}^{\mathrm{hu}} \sum_{\mathrm{t}=1}^{\mathrm{tu}} \widetilde{\mathrm{K}}_{\mathrm{intt}} * \mathrm{VE}_{\mathrm{inht}}\left(1+\mathrm{e}_{\mathrm{k}}\right)^{\mathrm{h}-1} \\
& +\sum_{\mathrm{i}=1}^{\mathrm{m}} \sum_{\mathrm{n}=1}^{\mathrm{nu}} \sum_{\mathrm{h}=1}^{\mathrm{hu}} \widetilde{\mathrm{K}}_{\mathrm{in} 1 \mathrm{td}} * \mathrm{VE}_{\text {inhtd }}\left(1+\mathrm{e}_{\mathrm{k}}\right)^{\mathrm{h}-1}+\sum_{\mathrm{n}=1}^{\mathrm{nu}} \sum_{\mathrm{h}=1}^{\mathrm{hu}} \sum_{\mathrm{t}=1}^{\mathrm{tu}} \widetilde{\mathrm{K}}_{\mathrm{dn} 1 \mathrm{t}} * \mathrm{VE}_{\text {dnht }}\left(1+\mathrm{e}_{\mathrm{k}}\right)^{\mathrm{h}-1} \\
& +\sum_{\mathrm{n}=1}^{\mathrm{nu}} \sum_{\mathrm{h}=1}^{\mathrm{hu}} \widetilde{\mathrm{K}}_{\mathrm{dn} 1 \mathrm{tdd}} * \mathrm{VE}_{\mathrm{dnhtd}}\left(1+\mathrm{e}_{\mathrm{k}}\right)^{\mathrm{h}-1}+\sum_{\mathrm{t}=1}^{\mathrm{tu}} \sum_{\mathrm{n}=1}^{\mathrm{nu}} \sum_{\mathrm{h}=1}^{\mathrm{hu}} \sum_{\mathrm{j}=1}^{\mathrm{mp}} \mathrm{b}_{\mathrm{tn1j}} * \mathrm{VB}_{\mathrm{tnhj}}\left(1+\mathrm{e}_{\mathrm{b}}\right)^{\mathrm{h}-1} \\
& +\sum_{\mathrm{n}=1}^{\mathrm{nu}} \sum_{\mathrm{h}=1}^{\mathrm{hu}} \sum_{\mathrm{j}=1}^{\mathrm{mp}} \mathrm{b}_{\mathrm{tdn} 1 \mathrm{j}} * \mathrm{VB}_{\mathrm{tdnhj}}\left(1+\mathrm{e}_{\mathrm{b}}\right)^{\mathrm{h}-1}+\sum_{\mathrm{i}=1}^{\mathrm{m}} \sum_{\mathrm{n}=1}^{\mathrm{nu}} \sum_{\mathrm{h}=1}^{\mathrm{hu}} \mathrm{f}_{\mathrm{in1}} * \mathrm{xw}_{\mathrm{inh}}\left(1+\mathrm{e}_{\mathrm{f}}\right)^{\mathrm{h}-1} \\
& +\sum_{\mathrm{t}=1}^{\mathrm{tu}} \sum_{\mathrm{n}=1}^{\mathrm{nu}} \sum_{\mathrm{h}=1}^{\mathrm{hu}} \mathrm{f}_{\mathrm{tn} 1} * \mathrm{xv}_{\mathrm{tnh}}\left(1+\mathrm{e}_{\mathrm{f}}\right)^{\mathrm{h}-1}
\end{aligned}
$$


where $a_{i n 1}, a 1_{d n 1}, a 2_{d n 1}, c_{i n 1}, d_{i n 1}, K_{i n 1 t}, K_{i n 1}, K_{n 1 t}, K_{n 1}, b_{t n 1 j}, b_{t d n 1 j}, f_{i n 1}$ and $f_{t n 1}$ denote the cost coefficients. The total cost of each scenario is the sums of the manufacturing and distribution costs. Total cost of supply chain achieve from expected cost of all scenarios. In real-world situations, the interest factor commonly affects the value of total costs and a DM must consider the time value of money for each cost category in practical these problems. Therefore, the escalating factors in Eq. (1) represent the time value of money for operating cost categories. Additionally, the adjustment of cash flows to a common time basis is necessary when determining the time value of money. Within the subscripts of each operating cost category, 1 should replace the index $h$.

\subsubsection{Constraints}

\subsubsection{1. $\quad$ The demand constraints for each destination $j$}

$\sum_{\mathrm{t}=1}^{\mathrm{tu}} \mathrm{VB}_{\text {stnhj }}+\mathrm{VB}_{\text {stdnhj }}=\mathrm{D}_{\mathrm{nhj}} \quad \forall n, \forall \mathrm{h}, \forall j, \forall s$

In real-world situations, the sum of regular production, inventory levels and backorder levels coming from various sources should essentially be equal the demand of each destination, as in Eq. (2).

\subsubsection{The inventory levels constraints}

$$
\begin{aligned}
& \mathrm{VA}_{\text {sinh }}+\mathrm{VC}_{\text {sinh }-1} \times \mathrm{xc}_{\text {sinh }}+\mathrm{VD}_{\text {sinh-1 }} \times \mathrm{xc}_{\text {sinh }}-\sum_{\mathrm{t}=1}^{\mathrm{tu}} \mathrm{VE}_{\text {sinht }}-\mathrm{VE}_{\text {sinhtd }} \\
& =\mathrm{VC}_{\text {sinh }} \times \mathrm{xc}_{\text {sinh }}+\mathrm{VD}_{\text {sinh }} \times \mathrm{xc}_{\text {sinh }} \quad \forall n, \forall \mathrm{h}, \forall i, \forall s \\
& \mathrm{VA}_{\mathrm{sdnh}}+\mathrm{VAd}_{\mathrm{sdnh}}-\sum_{\mathrm{t}=1}^{\mathrm{tu}} \mathrm{VE}_{\mathrm{sdnht}}-\mathrm{VE}_{\mathrm{sdnhtd}}=0 \quad \forall n, \forall \mathrm{h}, \forall s
\end{aligned}
$$

Eq. (3) stands for the constraint that the demand for each destination over a particular period could be either satisfied or backordered by sources in disruption condition; however, the backorder must be fulfilled by sources in the next period. Eq. (4) states backup supplier must fulfill remain demand that cannot satisfy by other sources because of disruption.

\subsubsection{Balance of transshipments constraints}

$\sum_{\mathrm{i}=1}^{\mathrm{m}} \mathrm{VE}_{\text {sinht }}+\mathrm{VE}_{\text {sdnht }}=\sum_{\mathrm{j}=1}^{\mathrm{mp}} \mathrm{VB}_{\text {stnhj }} \quad \forall n, \forall \mathrm{h}, \forall t, \forall s$

$\sum_{\mathrm{i}=1}^{\mathrm{m}} \mathrm{VE}_{\text {sinhtd }}+\mathrm{VE}_{\text {sdnhtd }}=\sum_{\mathrm{j}=1}^{\mathrm{mp}} \mathrm{VB}_{\text {stdnhj }} \quad \forall n, \forall \mathrm{h}, \forall s$

Eq. (5) and Eq. (6) determine product volume, which must be received and sent for transshipment $t$ and backup transshipment $t d$ for product $n$ in period $h$.

\subsubsection{The production, transshipment capacity and warehouse space constraints}

$\mathrm{l}_{\mathrm{inh}} * \mathrm{VA}_{\sinh } \leq \mathrm{L}_{\mathrm{inh}} \times \mathrm{xw}_{\mathrm{inh}} \times \mathrm{xc}_{\sinh } \forall \mathrm{n}, \forall \mathrm{h}, \forall \mathrm{i}, \forall \mathrm{s}$

$\mathrm{r}_{\text {inh }} \mathrm{VA}_{\text {sinh }} \leq \mathrm{M}_{\mathrm{inh}} \times \mathrm{xw}_{\mathrm{inh}} \times \mathrm{xc}_{\text {sinh }} \forall n, \forall \mathrm{h}, \forall i, \forall s$

$\mathrm{st}_{\mathrm{tnh}} \times \sum_{\mathrm{j}=1}^{\mathrm{mp}} \mathrm{VB}_{\text {stnhj }} \leq \mathrm{Mt}_{\text {tnh }} \times \mathrm{xv}_{\text {tnh }} \times \mathrm{xt}_{\text {stnh }} \forall n, \forall \mathrm{h}, \forall t, \forall s$ 
$\mathrm{v}_{\mathrm{n}} \times \sum_{\mathrm{t}=1}^{\mathrm{tu}} \mathrm{VB}_{\text {stnhj }}+\mathrm{VB}_{\text {stdnhj }} \leq \mathrm{W}_{\text {nhj }} \forall n, \forall \mathrm{h}, \forall j, \forall s$

Eq. (7) and Eq. (8) represent the limits of available labor levels and machine capacity of each product for each source in each period, respectively. Eq. (9) represents the limits of capacity of each product for each transshipment in each period. Eq. (10) represents the limits of actual warehouse capacity in each period of each product for each destination.

\subsubsection{Non-negativity constraints}

$$
\begin{gathered}
\mathrm{VA}_{\text {sdnh }}, \mathrm{VAd}_{\text {sdnh }}, \mathrm{VA}_{\text {sinh }}, \mathrm{VB}_{\text {stnhj }}, \mathrm{VB}_{\text {stdnhj }}, \mathrm{VC}_{\text {sinh }}, \mathrm{VD}_{\text {sinh }}, \mathrm{VE}_{\text {sinht }}, \mathrm{VE}_{\text {sinhtd }}, \mathrm{VE}_{\text {sdnht }}, \mathrm{VE}_{\text {sdnhtd }} \\
\geq 0 \quad \forall t, \forall i, \forall n, \forall \mathrm{h}, \forall j, \forall s
\end{gathered}
$$

\subsection{Identifying disruption scenarios}

An important question associated with this model is to determine disruption scenarios. Consider a model, which has $m$ supplier and $t u$ transshipment center of $n u$ product at $h u$ period. Thus, Total possible scenario is $2^{(\mathrm{m}+\mathrm{tu}) * \mathrm{nu} * \mathrm{hu}}$. Obviously, increasing one unit of each segment that mentioned will increase the size of problem, exponentially. In practice, the number of considered scenarios is much smaller. To identify scenarios, decision makers use expert judgment. There are more options to start by identifying scenario, where one of them is a facility disrupt in one period caused by operation problem. Another possible scenario is a disruption with supplier in all period due to unexpected incidents such as fire. Sometimes, suppliers in an area are inactive because of disruption events such as earthquakes, electricity shortages, and so on. Note that probability of more than two facilities without any mentioned causes at the same time is very small. Other scenarios are achieved based on relationships between suppliers and decision maker judgment.

\subsection{Complexity}

Peng Peng et al. (2011) proved that this problem is NP-hard for single product and single period situation and the proposed model of this paper is also NP-hard.

\section{Hybrid meta-heuristic algorithm}

Practitioners are often more interested in obtaining near-optimal solutions in relatively short amount of time. Genetic algorithms (GA) are powerful global search heuristics inspired by evolution theory (Holland, 1975). GAs have gained popularity for their ease of implementation and successful application in a wide ranges of optimization and search problems (Gen \& Cheng, 2000). Peng Peng et al. (2011) used GA to solve problem in single period and single product situation with robust and expected cost optimization. However, their approach cannot solve this problem with multi period and multi product. Thus, we use a priority-based GA encoding to solve this problem that update to multi period and multi product state. Numerical experiments (Section 4) show that the algorithm outperforms LINGO in terms of CPU time and solution quality for most instances tested. Our GA encodes values for the locations of the supply, transshipment nodes and whether inventory is carried or not $(x v, x w, x w c$ variables). Once these variables are chosen, other variables are set optimally for each scenario by solving priority algorithm. Finally, expected cost is get from probability of each scenario and its cost.

\section{1. priority-based genetic algorithms}

Search techniques such as Branch and Bound that work on improving one single solution consume much memory and time to obtain best solution are also good methods to use. However, GAs that maintains a population of solutions spends relatively little effort on each one, time and memory. The name of each individual in the population is chromosome. A chromosome consists a solution to the 
problem and is often coded as a binary string of $0 \mathrm{~s}$ and $1 \mathrm{~s}$. To find the best solution or near best solution of a problem in genetic algorithm, one or several iterations may be needed. Each iteration contains a process that the population is updated called evaluation. Iteration after this process must be evaluated by every individual by fitness function. Finally, iteration is stochastically selected multiple individuals from current population based on their fitness and is formed for the next population (generation) by either merging two chromosomes using a crossover operation or modifying a chromosome using a mutation operation. Next iteration based on this population is performed through their process that explained. The GA is stopped when termination criteria such as the maximum number of iterations is met. To obtain comprehensive information on GAs and their applications, view Gen and Cheng (2000). Researcher and practitioner applied GAs to various facility location and network design problems and proved to be a very effective heuristic method to solve this type of problem, especially problems of large scale (see, e.g. Alp et al., 2003; Drezner \& Wesolowsky, 2003; Snyder \& Daskin, 2006).

In this paper, we apply a priority-based genetic algorithm to solve model by Gen et al. (2006). Different from the basic GA scheme, we apply a priority approach in GA, which not only considers position of gen in chromosome but also considers value of gen in its inside. Numerical tests show that this step greatly reduces the solution time. The details of our algorithm are described next.

\subsection{Representation scheme}

We use an n-digit binary string chromosome structure to represent a solution $X$, which composed of $x w, x v$ and $x w c$ variables where $n=|x w|+|x v|+|x w c|$. Each gene less than $|x w|+|x v|$ state related facility of product $n$ in a certain period is open (" 1 ") or not (" 0 "). And each gene else presents inventory level of each product in a certain period for next period is positive (" 1 ") or not (" 0 ").For example, in Fig. 1, Suppliers 1, 2 for product 1and 2 in period 1 are chosen in the current solution and transshipment 1 for product 1, 2 in period 1 are chosen in the current solution. Finally, supplier lcan carry inventory to next period for both product.

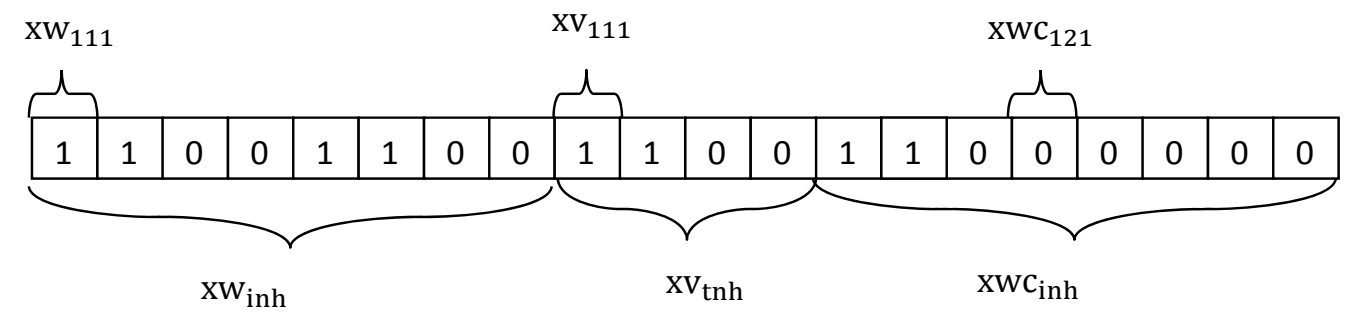

Fig. 1. Chromosome structure.

After we build the chromosome, we determine value of gens less than $|x w|+|x v|$ with fixed cost of use facility $i$ or $t$ for product $n$ in period $h$. For gens into $x w C$ segment, value of gens is carrying cost to next period or $\mathrm{c}_{\mathrm{inh}}$. For each scenario, we multiply parameter of the scenario to chromosome and do algorithm as follow:

\subsection{Algorithm}

After we determine decision variables in each scenario, we calculate cost of each scenario. Then we multiply this cost (scenario cost) to probability of scenario. The expected cost is summation of the results of each scenario.

\subsection{GA operators}

Two individuals are selected randomly from the current population by crossover operator. To generate new individuals, crossover operator chose some digits randomly on one of the chromosome and switch with the digit at same position on another chromosome (See Fig. 2). 
1. Sort gens which are open based on value (fixed cost) in $\mathrm{Xv}_{\mathrm{tnh}}$ segment of each chromosome.

2. For these gens calculate $\mathrm{MT}_{\mathrm{tnh}}=\mathrm{MT}_{\mathrm{tnh}} / \mathrm{st}_{\mathrm{tnh}}$.

3. For all destination calculate $\mathrm{W}_{\mathrm{nhj}}=\mathrm{W}_{\mathrm{nhj}} / \mathrm{v}_{\mathrm{n}}$

4. For transshipments from step 1 as $(\mathrm{t})$ do.

a. Sort destination (j) based on transshipment cost for each transshipment $(t) b_{t n h j}$ :

i. Allocate $\mathrm{VB}_{\text {tnhj }}=\min \left(\mathrm{D}_{\mathrm{nhj}}, \mathrm{W}_{\mathrm{nhj}}, \mathrm{MT}_{\mathrm{tnh}}\right)$.

ii. Update value of $\left(\mathrm{D}_{\mathrm{nhj}}\right),\left(\mathrm{W}_{\mathrm{nhj}}\right)$ and $\left(\mathrm{MT}_{\mathrm{tnh}}\right)$ as bellow:

1. $\mathrm{W}_{\text {nhj }}=\mathrm{W}_{\text {nhj }}-\mathrm{VB}_{\mathrm{tnhj}}$

2. $\mathrm{D}_{\mathrm{nhj}}=\mathrm{D}_{\mathrm{nhj}}-\mathrm{VB}_{\mathrm{tnhj}}$

3. $\mathrm{Mt}_{\mathrm{tnh}}=\mathrm{Mt}_{\mathrm{tnh}}-\mathrm{VB}_{\mathrm{tnh}}$

b. $\quad \operatorname{If}\left(D_{\text {nhj }}\right)=0$ or $\mathrm{W}_{\text {nhj }}=0$ select next $\mathrm{j}$ and go to step $\mathrm{i}$.

5. Allocate $\mathrm{VB}_{\mathrm{tdnhj}}=\mathrm{D}_{\mathrm{nhj}}$ for each remain demands for product $\mathrm{n}$ in period $\mathrm{h}$.

6. Determine demand of each transshipment as follow and called Dt

a. $\mathrm{Dt}_{\mathrm{tnh}}=\sum_{\mathrm{j}=1}^{\mathrm{mp}} \mathrm{VB}_{\mathrm{tnh}}$

b. $\mathrm{Dt}_{\mathrm{tdnh}}=\sum_{\mathrm{j}=1}^{\mathrm{mp}} \mathrm{VB}_{\mathrm{tdnh}}$

7. Sort gens which are open based on its value (fixed cost) in $\mathrm{Xw}_{\mathrm{inh}}$ segment.

8. For these gens calculate $\mathrm{Mi}_{\text {inh }}=\min \left(\frac{\mathrm{M}_{\mathrm{inh}}}{\mathrm{r}_{\mathrm{inh}}}, \frac{\mathrm{L}_{\mathrm{inh}}}{\mathrm{l}_{\mathrm{inh}}}\right)$ and from best to worst of gens do:

a. Sort transshipment nodes ( $\mathrm{t}$ ) based on cost of transportation for each supplier (i) as $\mathrm{k}_{\mathrm{inht}}$.

b. Determine volume transportation $V E_{\text {inht }}$ based on $\left(V_{i n h t}=\min \left(D t_{t n h}, M i_{i n h}\right)+V E_{i n h-1 t}\right)$

c. Update value of $\left(\mathrm{Dt}_{\mathrm{tnh}}\right)$ and $\left(\mathrm{Mi}_{\mathrm{inh}}\right)$.

i. $\mathrm{Dt}_{\mathrm{tnh}}=\mathrm{Dt}_{\mathrm{tnh}}-\mathrm{VE}_{\mathrm{inht}}$

ii. $\mathrm{Mi}_{\text {inh }}=\mathrm{Mi}_{\text {inh }}-\mathrm{VE}_{\text {inht }}$

d. If $\left(D t_{t n h}\right)$ equal zero, select next $t$ and go to step $b$.

9. If all $\left(\mathrm{Mi}_{\mathrm{inh}}\right)$ parameters are zero go to step 10. If all $\left(\mathrm{Dt}_{\mathrm{tnh}}\right)$ are zero go to step 13.

10. Achieve $P D t_{n h+1}=\left\{\min \left(\sum_{i=1}^{m} \mathrm{M}_{\mathrm{inh}+1}, \sum_{i=1}^{m} \mathrm{~L}_{\mathrm{inh}+1}\right)\right\}-\sum_{\mathrm{t}=1}^{\mathrm{tu}} D \mathrm{t}_{\mathrm{tnh}+1}$ and sort suppliers of product $\mathrm{n}$ in period $\mathrm{h}$ which capacity $\left(\mathrm{Mi}_{\mathrm{inh}}\right)$ is positive based on $\mathrm{d}_{\mathrm{inh}}$.

11. If $P D t_{n h+1}>0$.then for above set do:

a. $\quad$ allocate $\mathrm{VD}_{\mathrm{inh}}=\min \left(\mathrm{Mi}_{\mathrm{inh}+1}, \sum_{\mathrm{t}=1}^{\mathrm{tu}} \mathrm{Dt} \mathrm{t}_{\mathrm{tnh}}, P D t_{n h+1}\right)$.

b. Update $\mathrm{Mi}_{\mathrm{inh}+1}$ and $\mathrm{Dt}_{\mathrm{tnh}}$ as follow
i. $\mathrm{Mi}_{\mathrm{inh}+1}=\mathrm{Mi}_{\mathrm{inh}+1}-\mathrm{VD}_{\mathrm{inh}}$
ii. For $\mathrm{Dt}_{\mathrm{tnh}}>0$, then $\mathrm{VE}_{\mathrm{inht}}=\min \left(\mathrm{Dt}_{\mathrm{tnh}}, \mathrm{VD}_{\mathrm{inh}}\right)$
iii. For $D t_{t n h}>0$, then $D t_{\text {tnh }}=D t_{\text {tnh }}-V^{\prime} E_{\text {inht }}$.
iv. $P D t_{n h+1}=P D t_{n h+1}-\mathrm{VD}_{\text {inh }}$

c. If $\mathrm{Mi}_{\mathrm{inh}+1}=0$ and $\sum_{\mathrm{t}=1}^{\mathrm{tu}} \mathrm{Dt}_{\mathrm{tnh}} * P D t_{n h+1}>0$, go to next member of set in step 10 .

12. If $\sum_{\mathrm{t}=1}^{\mathrm{tu}} D \mathrm{t}_{\mathrm{tnh}}=0$ then go to step 20 and if $P D t_{n h+1}=0$ go to step 19.

13. Sort suppliers which $\mathrm{Mi}_{\text {inh }}$ are positive of product $\mathrm{n}$ in period $\mathrm{h}$.

14. For above set do:

a. Allocate $\mathrm{VE}_{\text {inhtd }}=\min \left(\mathrm{Dt}_{\mathrm{tdnh}}, \mathrm{Mi}_{\mathrm{inh}}\right)$

b. Update $\mathrm{Mi}_{\mathrm{inh}}$ and $\mathrm{Dt}_{\mathrm{tnh}}$ as follow

i. $\mathrm{Mi}_{\text {inh }}=\mathrm{Mi}_{\text {inh }}-\mathrm{VE}_{\text {inhtd }}$

ii. $\quad \mathrm{Dt}_{\mathrm{tdnh}}=\mathrm{Dt}_{\mathrm{tdnh}}-\mathrm{VE}_{\mathrm{inhtd}}$

c. If $\mathrm{Mi}_{\text {inh }}=0$, then go to next member.

15. Calculate $P C t_{n h+1}=\sum_{\mathrm{t}=1}^{\mathrm{tu}} \mathrm{Dt} \mathrm{t}_{\mathrm{tnh}+1}-\left\{\min \left(\sum_{i=1}^{m} \mathrm{M}_{\mathrm{inh}+1}, \sum_{i=1}^{m} \mathrm{~L}_{\mathrm{inh}+1}\right)\right\}$.

16. If $\left(\sum_{i=1}^{m} \mathrm{M}_{\mathrm{inh}}\right)$ and $P C t_{n h+1}$ are greater than zero then go to step 17, else go to step 19 .

17. Sort suppliers like $\mathrm{i}$ in each period and each product which $\mathrm{xWC}_{\mathrm{inh}}=1$ and $\mathrm{Mi}_{\mathrm{inh}}>0$ based on $\mathrm{c}_{\mathrm{inh}}$.

18. For above set do:

a. Allocate $\mathrm{VC}_{\mathrm{inh}}=\min \left(P C t_{n h+1}, \mathrm{Mi}_{\mathrm{inh}}\right)$.

b. Update $\mathrm{Mi}_{\mathrm{inh}}$ and $P C t_{n h+1}$ as follow
i. $\mathrm{Mi}_{\text {inh }}=\mathrm{Mi}_{\text {inh }}-\mathrm{VC}_{\mathrm{inh}}$
ii. $P C t_{n h+1}=P C t_{n h+1}-V_{i n h}$
iii. $\mathrm{Mi}_{\mathrm{inh}+1}=\mathrm{Mi}_{\mathrm{inh}+1}+\mathrm{VC}_{\mathrm{inh}}$.

c. If $\mathrm{Mi}_{\mathrm{inh}}=0$, then go to next member of set in step 18 .

19. AllocateVE $E_{\text {dnht }}=\sum_{\mathrm{t}=1}^{\mathrm{tu}} \mathrm{Dt}_{\mathrm{tnh}}$.

20. AllocateVE $\mathrm{dnhtd}_{\mathrm{d}}=\mathrm{Dt}_{\mathrm{tdnh}}$.

21. Determine $V A_{\text {inh }}=\sum_{\mathrm{t}=1}^{\mathrm{tu}} \mathrm{VE}_{\text {inht }}+\mathrm{VE}_{\text {inhtd }}$

22. Determine $\mathrm{VA}_{\mathrm{dnh}}=\min \left(\sum_{\mathrm{t}=1}^{\mathrm{tu}} \mathrm{VE}_{\mathrm{dnht}}+\mathrm{VE}_{\mathrm{dnhtd}}, x_{d n h}\right)$.

23. Determine $\mathrm{VAd}_{\mathrm{dnh}}=\sum_{\mathrm{t}=1}^{\mathrm{tu}} \mathrm{VE}_{\mathrm{dnht}}+\mathrm{VE}_{\mathrm{dnhtd}}-\mathrm{VA}_{\mathrm{dnh}}$. 
A probability is drawn uniformly from the set $\{0.0,0.1,0.2 \ldots 1.0\}$ for each pair, and each digit is swapped with that probability. To prevent the algorithm from becoming trapped in local optima and to ensure a diverse population, a mutation process must be done. Mutation selects $20 \%$ of chromosome in each population. Then, mutation selects gen of each chromosome randomly. Finally, Mutation changes these gens from 1 to 0 or 0 to 1, as shown in Fig. 3.

\begin{tabular}{|c|c|c|c|c|c|c|c|c|c|c|c|c|c|c|c|}
\hline 1 & 1 & 0 & 1 & 0 & 1 & 0 & 0 & $\rightarrow 0$ & 1 & 1 & 1 & 0 & 1 & 0 & 0 \\
\hline$\uparrow$ & & $\uparrow$ & $\uparrow$ & & & & & & & & & & & & \\
\hline 0 & 1 & 1 & 1 & 0 & 0 & 1 & 1 & $\rightarrow 1$ & 1 & 0 & 1 & 0 & 0 & 1 & 1 \\
\hline
\end{tabular}

Fig. 2. Crossover operation

\begin{tabular}{|l|l|l|l|l|l|l|l|}
\hline 1 & 1 & 0 & 1 & 0 & 1 & 0 & 0 \\
\hline 1 & 1 & 0 & 1 & 0 & 0 & 0 & 0 \\
\hline
\end{tabular}

Fig. 3. Mutation operation

\subsection{Termination criteria}

Many criteria exist to stop genetic algorithm as meet pre specified time or iteration limit and little improvement objective function for consecutive iterations. For our problem, we use second kind of criteria that select 0.00001 of the best solution for little improvement objective function and 10 iterations for number of consecutive iterations. To compare the best solution with the lower bound that calculated by LINGO, we use LP relaxation.

\section{Computational results}

We performed a series of numerical experiments to evaluate the performance of our algorithm. We coded the algorithm in MATLAB and executed it on a computer with an AMD Athlon X2 Neo $2.66 \mathrm{GHz}$ processor and $2 \mathrm{~GB}$ of RAM, operating under Microsoft Windows 7 Ultimate. We benchmark our results using the branch-and-bound algorithm in Lingo 11.0, which we ran on the same hardware. Computation times are reported in seconds.

\subsection{Experimental design}

To investigate of our model, we generate 45 random data sets of different size of our model. Size of our problem is 10, 15 and 20 for supplier nodes, 10,15 and 20 for transshipment nodes, 3 and 4 for products and 15, 20 and 25 for destination node in 3,5 and 7 periods and 25,36,49 and 64 scenarios. The resulting instances are labeled "m-tu-nu-hu-mp-sce" where "sce" is number of scenario which the probability of scenarios are equal. (For example, instance "10-20-4-7-20-64" has 10 supply nodes, 20 transshipment nodes, 4 products, 7 periods, 20 demand nodes, 64 scenarios). The fixed costs for supply nodes $\left(f_{\mathrm{in} 1}\right)$ and for transshipment nodes $\left(f_{\mathrm{tn} 1}\right)$ are drawn uniformly from $[200,235]$ and $[170,220]$, respectively. The unit transportation costs from transshipment nodes to destination nodes $b_{t n 1 j}$ and transportation costs from backup transshipment nodes to destination nodes $b_{t d n 1 j}$ are drawn uniformly from $[4,6]$ and $[25,30]$, respectively. In addition, the unit transportation costs from supply nodes to transshipment nodes $\mathrm{k}_{\mathrm{in} 1 \mathrm{t}}$ and transportation costs from supply nodes to backup transshipment nodes $\mathrm{k}_{\mathrm{in} 1 \mathrm{td}}$ are drawn uniformly from $[1,20]$ and $[26,41]$, respectively. Finally, the unit transportation costs from backup supplier to transshipment nodes $\mathrm{k}_{\mathrm{dn} 1 \mathrm{t}}$ and backup transshipment nodes $\mathrm{k}_{\mathrm{dn} 1 \mathrm{td}}$ are drawn uniformly from [42, 62] and [70, 85], respectively. Operation costs for supply nodes as production costs $a_{i n 1}$, carrying costs $c_{i n 1}$ and backorder costs $d_{i n 1}$ are drawn uniformly from $[10,13],[4,6]$ and $[90,100]$, respectively. Production costs for backup supply nodes as $\mathrm{a}_{\mathrm{dn} 1}$ and $\mathrm{ad}_{\mathrm{dn} 1}$ are [120 130] and [750 760] respectively. At each demand node, the parameter $D_{n h j}$ is drawn uniformly from [600, 1100]. At each supply nodes, the machine 
capacity $\mathrm{M}_{\mathrm{inh}}$ and labor level $\mathrm{L}_{\mathrm{inh}}$ are drawn uniformly from [200,1100] and [500,1000]. At each transshipment nodes, the capacity $\mathrm{Mt}_{\mathrm{tnh}}$ is drawn uniformly from [200, 900].finally, at each destination nodes the warehouse capacity $W_{\text {nhj }}$ is drawn uniformly from $[800,1200]$. The capacity of the emergency facility is always set to infinity but reserved capacity, which determine between back up supplier and logistic segment is 100 . The disruption scenarios are generated randomly until get sce unique scenarios.

\subsection{Algorithm performance}

We compare the performance of our GA with LINGO in Table 1.

Table 1

Algorithm performance - vs. LINGO

\begin{tabular}{|c|c|c|c|c|c|c|}
\hline \multirow[t]{2}{*}{ Test problem } & \multicolumn{2}{|c|}{ lingo } & \multicolumn{2}{|c|}{ GA } & \multicolumn{2}{|c|}{ Diff } \\
\hline & Time & Cost & Time & Cost & Time & Cost \\
\hline $10-10-3-5-15-25$ & 38.32903 & 120281067.8 & 50.43658 & 133353290.1 & $32 \%$ & $9.8 \%$ \\
\hline $10-10-3-5-15-36$ & 55.30912 & 143945594.8 & 78.66427 & 158824296.4 & $42 \%$ & $9.4 \%$ \\
\hline $10-10-3-5-15-49$ & 76.28904 & 143747764.7 & 83.29719 & 158612876.9 & $9 \%$ & $9.4 \%$ \\
\hline $10-10-3-5-15-64$ & 105.9592 & 148744814.9 & 97.13254 & 165922394.3 & $8 \%$ & $10.4 \%$ \\
\hline $10-10-4-5-15-25$ & 57.70918 & 162018844.5 & 65.06504 & 173845684.3 & $13 \%$ & $6.8 \%$ \\
\hline $10-10-4-5-15-36$ & 83.48927 & 242296863.2 & 54.83608 & 265588213.1 & $34 \%$ & $8.8 \%$ \\
\hline $10-10-4-5-15-49$ & 115.4193 & 270082708.4 & 94.17767 & 294610461.8 & $18 \%$ & $8.3 \%$ \\
\hline $10-10-4-5-15-64$ & 153.9793 & 167230061.4 & 101.9228 & 185131193.2 & $34 \%$ & $9.7 \%$ \\
\hline $10-10-3-7-15-25$ & 54.12935 & 185993844.6 & 43.47341 & 205385194.2 & $20 \%$ & $9.4 \%$ \\
\hline $10-10-3-7-15-36$ & 79.67941 & 266580367.2 & 75.44138 & 288398599.2 & $5 \%$ & $7.6 \%$ \\
\hline $10-10-3-7-15-49$ & 108.9894 & 266935813.1 & 95.20869 & 289751434.1 & $13 \%$ & $7.9 \%$ \\
\hline $10-10-3-7-15-64$ & 144.4394 & 264150503.5 & 94.28847 & 288338464.1 & $35 \%$ & $8.4 \%$ \\
\hline $10-10-4-7-15-25$ & 325.0291 & 462541249.8 & 47.62104 & 459711320.7 & $85 \%$ & $0.6 \%$ \\
\hline $10-10-4-7-15-36$ & 120.9496 & 343789092.5 & 52.35256 & 364711817.5 & $57 \%$ & $5.7 \%$ \\
\hline $10-10-4-7-15-49$ & 167.6495 & 345713905.6 & 64.82729 & 365788689.8 & $61 \%$ & $5.5 \%$ \\
\hline $15-10-4-5-20-25$ & 98.0683 & 307845383 & 46.2273 & 339127202.8 & $53 \%$ & $9.2 \%$ \\
\hline $15-10-4-5-20-36$ & 143.5983 & 307421922 & 67.27968 & 338900351.5 & $53 \%$ & $9.3 \%$ \\
\hline $15-10-4-5-20-49$ & 199.4183 & 282817140.1 & 110.3454 & 305210936.3 & $45 \%$ & $7.3 \%$ \\
\hline $15-10-4-5-20-64$ & 406.9083 & 282600558.8 & 129.7485 & 304956716.3 & $68 \%$ & $7.3 \%$ \\
\hline $15-10-4-7-20-25$ & 145.0583 & 361816788.9 & 53.6301 & 388642173.9 & $63 \%$ & $6.9 \%$ \\
\hline $15-10-4-7-20-36$ & 210.119 & 322355694.7 & 82.20221 & 351245706.4 & $61 \%$ & $8.2 \%$ \\
\hline $15-10-4-7-20-49$ & 422.639 & 322134158 & 116.4464 & 351020555.6 & $72 \%$ & $8.2 \%$ \\
\hline $15-15-3-5-20-25$ & 87.13816 & 262299028.5 & 57.65947 & 293321941.5 & $34 \%$ & $10.6 \%$ \\
\hline $15-15-3-5-20-36$ & 127.6182 & 225532974 & 81.69035 & 248474642 & $36 \%$ & $9.2 \%$ \\
\hline $15-15-3-5-20-49$ & 177.1682 & 177808755 & 123.4124 & 195946002.2 & $30 \%$ & $9.3 \%$ \\
\hline $15-15-3-5-20-64$ & 372.2482 & 239745119.3 & 152.2498 & 266406872.7 & $59 \%$ & $10.0 \%$ \\
\hline $15-15-3-7-20-25$ & 125.6282 & 359671417.9 & 70.34346 & 393693671.2 & $44 \%$ & $8.6 \%$ \\
\hline $15-15-3-7-20-36$ & 183.3482 & 426891462 & 103.7308 & 458722391 & $43 \%$ & $6.9 \%$ \\
\hline $15-15-3-7-20-49$ & 386.6582 & 354411010 & 125.6565 & 385831751.2 & $68 \%$ & $8.1 \%$ \\
\hline $20-15-4-5-25-25$ & 203.5893 & 371931435.8 & 68.74606 & 398991155.2 & $66 \%$ & $6.8 \%$ \\
\hline $20-15-4-5-25-36$ & 407.4993 & 441614755.2 & 93.05132 & 489555845.6 & $77 \%$ & $9.8 \%$ \\
\hline $20-15-4-5-25-49$ & 608.1494 & 287415466.2 & 142.6571 & 308145585.7 & $77 \%$ & $6.7 \%$ \\
\hline $20-15-4-5-25-64$ & 406.9083 & 282600558.8 & 129.7485 & 304956716.3 & $68 \%$ & $7.3 \%$ \\
\hline $20-15-3-7-25-25$ & 191.7193 & 412296295.4 & 84.49902 & 441014735.2 & $56 \%$ & $6.5 \%$ \\
\hline $20-15-3-7-25-36$ & 377.2193 & 411786908.8 & 97.9248 & 440826064.3 & $74 \%$ & $6.6 \%$ \\
\hline $20-15-3-7-25-49$ & $\mathrm{n} / \mathrm{a}$ & $\mathrm{n} / \mathrm{a}$ & 125.6565 & 385831751.2 & $\mathrm{n} / \mathrm{a}$ & $\mathrm{n} / \mathrm{a}$ \\
\hline $20-15-4-7-25-25$ & 295.5894 & 429032639.3 & 76.34809 & 455186753.1 & $74 \%$ & $5.7 \%$ \\
\hline $20-15-4-7-25-36$ & $\mathrm{n} / \mathrm{a}$ & $\mathrm{n} / \mathrm{a}$ & 82.20221 & 351245706.4 & $\mathrm{n} / \mathrm{a}$ & $\mathrm{n} / \mathrm{a}$ \\
\hline $20-15-4-7-25-49$ & $\mathrm{n} / \mathrm{a}$ & $\mathrm{n} / \mathrm{a}$ & 116.4464 & 351020555.6 & $\mathrm{n} / \mathrm{a}$ & $\mathrm{n} / \mathrm{a}$ \\
\hline $20-20-3-5-25-25$ & 168.3592 & 320919455.1 & 81.90629 & 347696952.7 & $51 \%$ & $7.7 \%$ \\
\hline $20-20-3-5-25-36$ & 241.9392 & 320337794.1 & 98.3552 & 347544924.1 & $59 \%$ & $7.8 \%$ \\
\hline $20-20-3-5-25-49$ & $\mathrm{n} / \mathrm{a}$ & $\mathrm{n} / \mathrm{a}$ & 123.4124 & 195946002.2 & $\mathrm{n} / \mathrm{a}$ & $\mathrm{n} / \mathrm{a}$ \\
\hline $20-20-3-5-25-64$ & $\mathrm{n} / \mathrm{a}$ & $\mathrm{n} / \mathrm{a}$ & 152.2498 & 266406872.7 & $\mathrm{n} / \mathrm{a}$ & $\mathrm{n} / \mathrm{a}$ \\
\hline
\end{tabular}


The "Test Problem" column gives the instance name. For each solution procedure as genetic algorithm and LINGO, two columns report the run time ("Time") and objective value ("Cost"). The CPU times for them include the time required to compute the optimal scenario costs. The two procedures are compared in the ("\% DIFF") column, where the ("Time") column gives the percentages of LINGO's CPU time required by our GA and the ("Cost') gives the percent difference between the objective function values. A value less than $100 \%$ in the ("Cost") column indicates that our algorithm found a better solution, while a value less than $100 \%$ in the ("Time') column indicates that our algorithm was faster, which occurs in all instances. As shown in Table 1, when compared with LINGO, our algorithm was able to find the better solutions in shorter time. In this table, n/a state a LINGO cannot solve it, because lack of memory on our system. Gap of cost of our algorithm is less than $10 \%$ and average gap of time of our algorithm is $47 \%$ in our numerical example.

\section{Conclusion}

In this paper, we have presented a multi segment multi product multi period supply chain network design model, which minimizes the expected cost. We propose an algorithm based on GA-priority to solve the model, and computational experiments show that we can obtain quality solutions that are very close to optimal given a fraction of the time required by LINGO. This makes our heuristic attractive in situations in which numerous experiments must be carried out and obtaining highquality, near optimal solutions in a short period of time is desired. The scenario approach can also be adopted to model other sources of uncertainties, such as customer demands, transportation costs, and so on. It is also possible to consider network design together with other supply chain problems, such as capacity expansion, vehicle routing, and so on, where traditional results are often in conflict with the objective of designing for disruptions.

\section{Acknowledgment}

The authors would like to thank the anonymous referees for earlier comments on this work, which improved the quality of the work.

\section{References}

Alp, O., Erkut, E., \& Drezner, Z. (2003). An efficient genetic algorithm for the p -median problem. Annals of Operations Research, 122 (1-4), 21-42.

Barrionuevo, A., \& Deutsch, C. (2005). A distribution system brought to its knees. New York Times, September 1.

Bathgate, A., \& Hayashi, A. (2008). Airlines lining up for Boeing 787 compensation. Reuters, April 10.

Berman, O., Krass, D., \& Menezes, M.B.C. (2007). Facility reliability issues in network p -median problems: strategic centralization and co-location effects. Operations Research, 55 (2), 332-350.

Bunschuh, M., Klabjan, D., \& Thurston, D. (2006). Modeling robust and reliable supply chains. Working Paper, University of Illinois at Urbana-Champaign, Urbana, IL 61801, USA.

Clark, D., \& Takahashi, Y. (2011). Quake disrupts key supply chains. The Wall Street Journal Asia, March 12.

Cui, T., Ouyang, Y., \& Shen, Z.-J.M. (2010). Reliable facility location design under the risk of disruptions. Operations Research, 58 (4-Part-1), 998-1011. 
Daskin, M., Snyder, L., \& Berger, R. (2005). Facility location in supply chain design. In: Langevin, A., Riopel, D. (Eds.), Logistics Systems: Design and Operation. Springer, New York, pp. 39-66, Chapter 2.

Drezner, Z. (1987). Heuristic solution methods for two location problems with unreliable facilities. The Journal of the Operational Research Society, 38(6), 509-514.

Drezner, Z., \& Wesolowsky, G. (2003). Network design: selection and design of links and facility location. Transportation Research Part A, 37(3), 241-256.

Gen, M., \& Cheng, R. (2000). Genetic Algorithms and Engineering Optimizations. Wiley, New York.

Gen, M., Altiparmak, F., Lin, L. (2006). A genetic algorithm for two-stage transportation problem using priority-based encoding. OR Spectrum, 28(3), 337-354.

Holland, J. (1975). Adaptation in natural and artificial systems: an introductory analysis with applications to biology, control, and artificial intelligence. University of Michigan Press, Michigan.

Kleindorfer, P., \& Saad, G. (2005). Managing disruption risks in supply chains. Production and Operations Management, 14(1), 53-68.

Latour, A. (2001). Trial by fire: A blaze in Albuquerque sets off major crisis for cell-phone giants Nokia handles supply chain shock with aplomb as Ericsson of Sweden gets burned - was Sisu the difference? Wall Street Journal, A1, January 29.

Li, X., \& Ouyang, Y. (2010). A continuum approximation approach to reliable facility location design under correlated probabilistic disruptions. Transportation Research Part B, 44 (4), 535548.

Lim, M., Daskin, M.S., Bassamboo, A., \& Chopra, S. (2009). Facility location decisions in supply chain networks with random disruption and imperfect information. Working Paper, Department of Industrial Engineering and Management Sciences, Northwestern University, Evanston, IL.

Lim, M., Daskin, M.S., Bassamboo, A., \& Chopra, S. (2010). A facility reliability problem: formulation, properties and algorithm. Naval Research Logistics, 57, 58-70.

Magnanti, T., \& Wong, R. (1984). Network design and transportation planning: models and algorithms. Transportation Science, 18(1), 1-55.

Meixell, M., \& Gargeya, V. (2005). Global supply chain design: a literature review and critique. Transportation Research Part E, 41(6), 531-550.

Mouawad, J. (2005). Katrina's shock to the system. The New York Times, September 4.

Owen, S., \& Daskin, M. (1998). Strategic facility location: a review. European Journal of Operational Research, 111(3), 423-447.

Peng, P., Snyder, L. V., Lim, A., \& Liu, Z. (2011). Reliable logistics networks design with facility disruptions. Transportation Research Part B: Methodological, 45(8), 1190-1211.

Scapparra, M., \& Cappanera, P. (2010). Optimal allocation of protective resources in shortest-path networks. Transportation Science, 45 (1), 64-80.

Shen, Z.-J.M., Zhan, R.L., \& Zhang, J. (2007). The reliable facility location problem: Formulations, heuristics, and approximation algorithms. Working Paper, Department of Industrial Engineering and Operations Research, University of California at Berkeley.

Snyder, L. (2006). Facility location under uncertainty: a review. IIE Transactions, 38(7), 537-554.

Snyder, L., \& Daskin, M. (2005). Reliability models for facility location: the expected failure cost case. Transportation Science, 39(3), 400-416.

Snyder, L., \& Daskin, M. (2006). A random-key genetic algorithm for the generalized traveling salesman problem. European Journal of Operational Research, 174 (1), 38-53.

Snyder, L., Scaparra, M., Daskin, M., \& Church, R. (2006). Planning for disruptions in supply chain networks. In: Greenberg, H. (Ed.), Tutorials in operations research. INFORMS, Baltimore, 234 257.

Tang, C. (2006). Robust strategies for mitigating supply chain disruptions. International Journal of Logistics Research and Applications, 9(1), 33-45. 
Zhan, R.L., Daskin, M.S., \& Shen, Z.-J.M. (2008). Facility reliability with site-specific failure probabilities. Working Paper, Department of Industrial Engineering and Operations Research, University of California-Berkeley. 